\title{
Efficacy and safety of serial membrane sweeping to prevent post term pregnancy: a randomised study
}

\author{
Sabita Saichandran*, Arthy Arun, Sunita Samal, Pallavee Palai
}

Department of Obstetrics \& Gynecology, Mahatma Gandhi Medical College \& Research Institute, Puducherry, India

Received: 18 September 2015

Accepted: 30 October 2015

\section{*Correspondence:}

Dr. Sabita Saichandran,

E-mail: sabita.kutty@gmail.com

Copyright: (C) the author(s), publisher and licensee Medip Academy. This is an open-access article distributed under the terms of the Creative Commons Attribution Non-Commercial License, which permits unrestricted non-commercial use, distribution, and reproduction in any medium, provided the original work is properly cited.

\begin{abstract}
Background: Prolonged pregnancy is associated with increased perinatal mortality and morbidity. Elective induction of labor at 41 weeks gestation is practiced routinely to improve the outcome. Membrane sweeping is old and simple method to promote onset of labor. To improve the success rate of this method, multiple attempts of sweeping has been tried and found to be effective and safe. Our aim was to assess the safety and efficacy of serial membrane sweeping in prevention of post term pregnancies.

Methods: Participants were randomly assigned to serial membrane sweeping every 48 hours starting from 40 weeks until the labour commencement or up to 41 weeks of gestation. There was no intervention up to 41 weeks in the control group. Labor was induced in women of both the groups who continued pregnancy beyond 41 weeks. Outcome measures include spontaneous onset of labor, mode of delivery, need of oxytocin for augmentation and maternal and fetal complications.

Results: Significant number of women had spontaneous onset of labor before 41 weeks (47/48) and delivered vaginally in contrast to control group (23/50). There is significantly less need of oxytocin in study group. The prevention remained consistent and not dependent on parity and bishop score. Significant number in control group had meconium stained liquor. No other maternal or fetal complications noted.

Conclusions: Serial membrane sweeping is both safe and effective in the prevention of pregnancy beyond 41 weeks. Hence reduces the post term pregnancy, need for induction of labour and related risks in low pregnancies.
\end{abstract}

Keywords: Serial membrane sweeping, Prevention of post term pregnancies

\section{INTRODUCTION}

Post-term or prolonged pregnancy is defined as a pregnancy that continues to or beyond 42 weeks (294 days) from the first day of the last menstrual period or 14 days beyond the best obstetric estimate of the date of delivery. ${ }^{1}$ Whereas Divon et al reported the functional definition of prolonged pregnancy as the period from $283^{\text {rd }}$ day as this is the gestational age at which the fetal mortality continues to increase without reduction in neonatal mortality. ${ }^{2}$

The reported incidence of post-term pregnancy ranges from $4-18 \%$ and is associated with increased perinatal morbidity and mortality. ${ }^{3,4}$

The Hannah review, the most recent Cochrane review and RCOG (Royal College of Obstetrics and Gynaecology) guidelines (Evidence-based Clinical Guidelines number 9) recommend that induction of labour should be offered at 41 weeks. ${ }^{5,6}$ In our institution we practice elective induction of labour at or beyond 41 weeks in women with low risk pregnancies using cervical ripening agents whenever needed. The cervical ripening agents may reduce the risks associated with induction of labor but cannot alleviate completely. 
Sweeping the membrane is an old and simple method to promote spontaneous onset of labour. ${ }^{7}$ It decreases the incidence of prolonged pregnancy and reduces the need for the use of formal method of induction of labour8. Membrane sweeping causes increased local production of prostaglandin and thererby increased levels of its metabolites in the maternal circulation enhancing the ripening of cervix leading on to spontaneous onset of labor. ${ }^{9,10}$ The plasma prostaglandins concentration after sweeping is $10 \%$ of those achieved in labour. ${ }^{11}$ Chorioamnionitis, premature rupture of membranes and bleeding from undiagnosed placenta previa are mentioned theoretically as risks of membrane sweeping. However in review of a clinical trial there was no increased incidence of fetal infection or neonatal morbidity related to this procedure. Maternal morbidity during membrane sweeping is related mainly to significant discomfort or pain, bleeding and contractions not leading to labor within 24hrs. ${ }^{12,13}$ In several trials sweeping has been reported as an effective method to reduce the number of pregnancies exceeding 41 weeks. ${ }^{14-17}$ Some studies have noted no reduction in the need for post-term induction with a single attempt of membrane sweeping whereas multiple attempts may be more efficacious. ${ }^{18} \mathrm{~A}$ recently published RCT by de Mirande et al and the recent Cochrane review showed that serial sweeping of the membranes decrease the incidence of prolonged pregnancies. ${ }^{19}$ Our aim is to assess the safety and effectiveness of serial membrane sweeping starting at 40 weeks in preventing the incidence of post-term pregnancies among the low risk group.

\section{METHODS}

The study included: a) uncomplicated singleton pregnancies with cephalic presentation and intact membranes, b) candidates for vaginal delivery, c) gestational age $40+0$ weeks and d) primigravida /primipara. The cases with scarred uterus or speculum findings suggestive of vaginal infection are excluded from this study.

After confirming the gestational age (Clinical criteria used to confirm gestational age - data from ACOG Practice Bulletin No 55), informed consent was obtained from low risk pregnant women who satisfied the inclusion criteria. The participants of the study were allocated randomly by the use of sealed opaque envelops for study and control groups. In the study group vaginal examination was performed for pelvic assessment and Bishop Score. During examination if the cervix is admitting a finger the fetal membranes are separated from the cervix and lower uterine segment as far as possible by sweeping a finger through 360 degrees. When the cervix is closed, attempts to stretch the cervix open or cervical massage was performed. Similar procedure was repeated every 48 hours till $41 \pm 0$ weeks (i.e. $40 \pm 0,40 \pm 3$, and $40 \pm 5$ ) or until labor commenced, whereas in the control group no pelvic examination was performed till the onset of labour or time of induction i.e. $41 \pm 0$ weeks. This is to avoid stimulation with cervical examination which can also raise the prostaglandin concentration causing ripening of the cervix. Both the groups were monitored by NST (daily) and AFI (once in every three days). Any conditions warranting immediate delivery were excluded from the study and were managed according to the institute protocol. Primary and secondary outcomes were assessed.

The ethical committee of our medical college approved the study. Primary outcome measures were the number of patients who had spontaneous onset of labour and any maternal or fetal complications. Secondary outcome measures included any use of oxytocin in labor, sweeping to delivery interval, mode of delivery, requirement of inducing agents and their dose; induction delivery interval, APGAR score and birth weight of all the babies were noted. Chi-square test was used and the results were considered statistically significant at $\mathrm{P}<0.05$.

\section{RESULTS}

A total number of 100 women satisfying the inclusion criteria were admitted on the day of expected date of delivery, that is, 40 completed weeks. These 100 women were randomized to study and control groups. The study group underwent membrane sweeping and control group did not undergo membrane sweeping. Two among the study group who required immediate induction of labor after the first sweeping were excluded from the final analysis. Hence the final analysis included 48 women in the study group and 50 women in the control group. There was no significant difference in the age group and the parity of the subjects in both control and study groups (Table 1). Among the outcome indicators studied, spontaneous onset of labor, pregnancies continued beyond 41 weeks, mode of delivery and the use of oxytocin for augmentation showed statistically significant difference between the study and the control groups and there was no significant difference in terms of neonatal outcome (Table 2). 29 out of 48 required more than one sweep to have spontaneous onset of labor (Table 3).

Table 1: Age group and parity of the subjects among study and control groups.

\begin{tabular}{|c|c|c|c|}
\hline No. of subjects & $\begin{array}{l}\text { Study } \\
\text { group }\end{array}$ & Control & Significance \\
\hline Age (years) & 50 & 50 & \\
\hline Primi & $18-29$ & $19-29$ & NS \\
\hline Multi & $36(72 \%)$ & $31(62 \%)$ & NS \\
\hline No. of subjects & $14(28 \%)$ & $19(38 \%)$ & \\
\hline
\end{tabular}

\section{DISCUSSION}

Sweeping the membrane is an old and simple method to promote spontaneous onset of labor, it decreases the incidence of post term pregnancy and reduces the need of the use of formal method of induction of labor. Its safety has been confirmed in almost all the studies (Berghella et 
Table 2: Outcome.

\begin{tabular}{|c|c|c|c|c|c|}
\hline Sr. No & \multicolumn{2}{|c|}{ Out come } & $\begin{array}{l}\text { Study group } \\
\quad(\mathrm{n}=48)\end{array}$ & Control $(\mathrm{n}=50)$ & $\begin{array}{l}\text { Significance } \\
\text { P value }\end{array}$ \\
\hline 1. & \multicolumn{2}{|c|}{ Spontaneous onset of labor } & 47 & 23 & \\
\hline 2. & \multicolumn{2}{|c|}{$\begin{array}{l}\text { Pregnancies continued beyond } 41 \\
\text { weeks/induction of labor done }\end{array}$} & 1 & 27 & $<0.001(\mathrm{~S})$ \\
\hline \multirow[t]{2}{*}{3.} & \multirow[t]{2}{*}{ Mode of delivery } & a. Vaginal & 48 & 40 & \\
\hline & & b. LSCS & 0 & 10 & $0.003(\mathrm{~S})$ \\
\hline \multirow[t]{2}{*}{4.} & \multirow{2}{*}{$\begin{array}{l}\text { Use of oxytocin } \\
\text { for augmentation }\end{array}$} & No & 33 & 10 & \\
\hline & & Yes & 15 & 40 & $<0.001(\mathrm{~S})$ \\
\hline \multirow[t]{2}{*}{5.} & \multirow[t]{2}{*}{ MSL } & No & 43 & 23 & \\
\hline & & Yes & 5 & 27 & $\mathrm{~S}$ \\
\hline 6. & \multicolumn{2}{|c|}{ Good APGAR score* } & 44 & 44 & \\
\hline \multirow[t]{4}{*}{7.} & \multirow[t]{4}{*}{ Birth weight $(\mathrm{Kg})$} & a. $\leq 2.5$ & 11 & 11 & \\
\hline & & b. $\quad 2.6-3.0$ & 19 & 25 & \\
\hline & & c. $3.1-3.5$ & 12 & 9 & \\
\hline & & d. $>3.5$ & 8 & 5 & \\
\hline
\end{tabular}

(* The APGAR score was 2-4 in the first minute and normal at 5th minute in 4 of the study group and 6 of the control group)

Table 3: Number of sweeps required for onset of labor.

\begin{tabular}{|lccc|}
\hline No. of sweeps required & 1 & 2 & 3 \\
\hline No. of cases & 18 & 21 & 8 \\
\hline
\end{tabular}

Table 4: Bishop score in relation to spontaneous labor from last sweep.

\begin{tabular}{|c|c|c|c|}
\hline \multirow{2}{*}{\multicolumn{2}{|c|}{$\begin{array}{l}\text { Bishop score } \\
\text { Total no (50) }\end{array}$}} & \multicolumn{2}{|c|}{$\begin{array}{l}\text { Spontaneous labor \& delivery } \\
\text { from last sweep Total (47) }\end{array}$} \\
\hline & & $<24$ hours & $>24$ hours \\
\hline$<5$ & 41 & 26 & 12 \\
\hline$>5$ & 9 & 9 & - \\
\hline
\end{tabular}

al, 1996; ${ }^{20}$ Magnann et al,1998 ${ }^{21}$ ). It has been used to shorten the length of pregnancy. ${ }^{20,22,23}$ However, all those studies reported either single or serial membrane sweepings from 38 weeks onwards. The rationale for performing routinely an intervention with the potential to induce labor in women with uneventful pregnancy at 38 weeks gestation seems to have little justification, as the perinatal morbidity and mortality start increasing from 41 weeks and even earlier like $40 \pm 3$ weeks period of gestation. Whereas in our study we included women who completed 40 weeks and had undergone serial sweepings by 41 weeks (study group). The women who did not have spontaneous labor were induced according to our institutional protocol at 41 weeks.

The control group was also admitted for antepartum surveillance. Bishop's score was assessed only at 41 weeks.(i.e. before induction of labor), as pelvic examination can itself increase the prostaglandin levels causing ripening of the cervix. ${ }^{9}$ In some studies gentle cervical examination was performed in the control group and this could influence the results..$^{8,20,23}$
In our study, 50 women underwent membrane sweeping (study group) and 50 did not have sweeping done (control group). Out of the fifty in the study group, 2 were excluded due to requirement of immediate induction of labor. Among these 48 cases, 47 had spontaneous labor and vaginal delivery; the remaining one had cervical massage thrice and was induced at 41 completed weeks succeeded by vaginal delivery. Whereas in control group 23 , had spontaneous onset of labor, out of which 22 had normal vaginal delivery and the remaining one had cesarean section for fetal distress. Spontaneous onset of labor was noticed in almost all the patients who are highly significant in the study group in contrast to the control group. The incidence of prolonged pregnancy was $2.08 \%$ in the study group and $54 \%$ in the control group.

Efficacy of sweeping of membranes has been proved in several studies like Swann 1958, ${ }^{24}$ Weissberg and Spellacy in $1977,{ }^{25}$ Epley et al1984; ${ }^{26}$ El Turkey and grant et al $1992^{16}$ with spontaneous onset of labor between $44-89 \%$ and Berghella et $\mathrm{al}^{20}$ the incidence of post-term pregnancy being $2.1 \%$ which is lower than that of general population. Our study also shared the same rate of post-term pregnancy in sweeping group.

In our study parity is almost equally distributed and majority had Bishop's score less than 5. Irrespective of Bishop's score and parity 47 out of 48 of the study group had spontaneous onset of labor. So, the parity and Bishop's score does not have any association with efficacy of membrane sweeping. Berghella study and Mecolgin et al reported that membrane sweeping is more effective in reducing the length of pregnancy and incidence of prolonged gestation in women with unfavorable Bishop's score. Miranda et al observed the effects of sweeping being restricted to the parous women. ${ }^{19}$ Foong et al demonstrated that sweeping of membrane during induction of labor had beneficial effect 
on labor and delivery which was limited to nullipara with unfavorable cervix. ${ }^{27}$ Bishop's score and parity did not have any correlation with sweeping to delivery interval in our study. In the study group, 34 delivered within 24 hours from the last sweep. Majority had spontaneous onset of labor with two sweepings and many of them delivered within 24 hours.

We did not notice any meconium aspiration syndrome though 5 cases were with meconium stained liquor. None of the neonates required intensive care. Whereas in the control group, 27 cases were with meconium stained liquor and 6 cases had poor Apgar score at 1 minute; none of the babies had any morbidity. Probably physiological maturation explains the high incidence of meconium stained liquor in our control group as there was no associated neonatal morbidity.

In our study 2 patients had premature rupture of membranes followed by spontaneous onset of labor and normal vaginal delivery. Whereas in Dare et $\mathrm{al}^{8}$ and Berghella $^{20}$ observed no case of premature rupture of membranes in their studies; E de Miranda et al, ${ }^{19}$ showed that premature rupture of membranes was equal in both the groups. There was no incidence of chorioaminionitis or bleeding per vagina in our study.

The outcome in the control group, in terms of the mode of, was comparable with that of other studies. The oxytocin requirement for augumentation was significantly less in our study group. Tan et al in their study demonstrated that few women who underwent membrane sweeping required oxytocin for shorter duration during induction of labor. ${ }^{28}$

\section{CONCLUSIONS}

Serial sweeping of the membranes is both safe and effective in the prevention of pregnancy beyond 41 weeks and hence reduces the incidence of post-term pregnancy, its risks and the related costs in uncomplicated pregnancies.

\section{Funding: No funding sources}

Conflict of interest: None declared

Ethical approval: The study was approved by the Institutional Ethics Committee

\section{REFERENCES}

1. American College of Obstetricians and Gynecologists. Management of Postterm Pregnancy. ACOG Practice Bulletin No.55. Washington, DC: ACOG. 2004.

2. Divon, MY, Ferber, A, Sanderson, $M$ et al. A functional definition of prolonged pregnancy based on daily fetal and neonatal mortality rates. Ultrasound Obstet Gynecol. 2004;23:423.

3. Bakketeig L, Bergsjo P. Postterm pregnancy: magnitude of the problem. In Chalmers I, Enkin
MW, Keirse MJNC, editors. Effective Care in pregnancy and Childbirth. Oxoford, UK: Oxoford University Press.1989;765-75.

4. Hilder L, Costeloe K, Thilaganathan B. Prolonged pregnancy: Evaluating gestation specific risks of fetal and infant mortality. BJOG. 1998;105:169-73.

5. Hannah ME. Postterm pregnancy: should all women have labour induced? A review of the literature. Fetal and Maternal Medicine Review. 1993;5:3-17.

6. Royal College of Obstetricians and Gynecologists. Induction of labour. Evidence based clinical Guideline No. 9, June 2001. London: RCOG Press.

7. Munro KJ, Jhonson RW, Philips MH. Historical Review of British Obstetrics and Gynaecology. 1800-1950. Edinburgh,UK: Livingstone, 1954.

8. Dare FO, Oboro VO. The role membrane stripping in prevention of post term pregnancy: a randomized clinical trial in Ile-Ife, Nigeria. J Obstet Gynaecol. 2002;22:283-6.

9. Mitchell MD, Flint APF, Bibby J, Brunt J, Anderson ABM, Turnbull AC. Rapid increase in plasma prostaglandin concentrations after vaginal examination and amniotomy. $\mathrm{Br}$ Med J. 1977;2:1183-5.

10. Keirse MJ, Thiery M, Parewijck W, Mitchell MD. Chronic stimulation of uterine prostaglandin synthesis during cervical ripening before the onset of labor. Prostaglandins. 1983:25:671-82.

11. McColgin SW, Bennet WA, Roach H, Cowan BD, Martin JN, Morrison JC. Parturitional factors associated with membrane stripping. Am J Obstet Gynecol. 1993;169:71-7.

12. Boulvain $\mathrm{M}$, Irion $\mathrm{O}$, Marcoux $\mathrm{S}$, Fraser $\mathrm{W}$. Sweeping the membranes to prevent post-term pregnancy and to induce labour: a systematic review. Br J Obstet Gynaecol. 1999;106(5):481-5.

13. Boulvain $M$, Irion $O$. Stripping/sweeping the membranes for inducing or preventing post-term pregnancy. Cochrane Database Syst Rev. 2004;(3):CD001328.

14. Wiriyasirizvaj B, Vutyavanich T, Ruangsri R. A randomized controlled trial of membrane stripping at term to promote labour. Obstet Gynecol. 1996;87:767-70.

15. Goldenberg M, Dulitzky M, Feldman B, Zolti M, Bider D. Stretching of the cervix and stripping of the membranes at term: a randomized controlled study. Eur J Obstet Gynecol Reprod Biol. 1996;66:129-32.

16. el-Torkey M, Grant JM. Sweeping of the membranes is an effective method of induction of labour in prolonged pregnancy. $\mathrm{Br} \mathrm{J}$ Obstet Gynaecol. 992;99(6):455-8.

17. Cammu H, Haitsma V. Sweeping of the membranes at 39 weeks in nulliparous women: a randomized controlled trial. $\mathrm{Br} \quad \mathrm{J}$ Obstet Gynaecol. 1998;105(1):41-4.

18. Wong SF, Hui SK, Choi H, Ho LC. Sweeping of membranes in formal induction of labour. BJOG. 2002;109:632-5. 
19. de Miranda E, van der Bom JG, Bonsel GJ, Bleker OP, Rosendaal FR. Membrane sweeping and prevention of post-term pregnancy in low-risk pregnancies: a randomized controlled trial. BJOG. 2006;113:402-8.

20. Berghella V, Rogers RA, Lescale K. Stripping of membranes as a safe method to reduce prolonged pregnancies. Obstet Gynecol. 1996;87:927-31.

21. Magann EF, McNamara MJ, Whitworth NS, Chauhan SP, Thorpe RA, Morrison JC: Can we decrease postdatism in women with an unfavourable cervix and a negative fetal fi bronectin test result at term by serial membrane sweeping? Am J Obstet Gynecol. 1998;179:890-4.

22. McColgin SW, Patrissi GA, Morrison JC: Stripping the fetal membranes at term: is the procedure safe and effi cacious? J Reprod Med. 1990;35:811-4.

23. Gupta R, Vasishta K, Sawhney H, Ray P: Safety and effi cacy of stripping of membranes at term. Int $\mathrm{J}$ Gynaecol Obstet. 1998;60:115-121.
24. Swann, RO. Induction of labour by stripping membranes. Obstet Gynecol. 1958;11:74-8.

25. Weissberg, SM, Spellacy, WM. Membrane stripping to induce labour. J Reprod Med. 1977;19:125-127.

26. Epley SL, Johnson SR, Goplerud CP. The morbidity of membrane stripping. J Iowa Med Soc. 1984;74:252-5.

27. Foong LC, Vanaja K, Tan G, Chua S. Membrane sweeping in conjunction with induction. Obstet Gynecol. 2000;96:539-42.

28. Tan PC, Jacob R, Omar SZ .Membrane sweeping at initiation of formal labor induction: a randomized controlled trial. Obstet Gynecol. 2006:107(3):569_ 77 .

Cite this article as: Saichandran S, Arthy A, Samal S, Palai P. Efficacy and safety of serial membrane sweeping to prevent post term pregnancy: a randomised study. Int J Reprod Contracept Obstet Gynecol 2015;4:1882-6. 